\title{
Application of Queuing Theory to Patient Satisfaction at Combined Hospital, Srinagar Garhwal Uttarakhand
}

\author{
Nidhi Malik ${ }^{1}$, O. K. Belwal ${ }^{2}$ \\ ${ }^{1}$ Research Scholar, Department of Statistics, Hemvati Nandan Bahuguna Garhwal (A Central) University, Srinagar Garhwal, Uttarakhand \\ ${ }^{2}$ Professor, Department of Statistics, Hemvati Nandan Bahuguna Garhwal (A Central) University, Srinagar Garhwal, Uttarakhand
}

\begin{abstract}
In today's stressful life, taking care of your health has become very important, and because of it, now a days there is a very heavy burden of patients on the private clinics, hospitals and other organizations taking care of ill and injured people. In these organizations patients arrive, wait for service, obtain service, and then depart, which is a queuing system. As queuing theory is the mathematical approach to analyze the waiting lines in any setting where arrival rate of subjects is faster than the system can handle. It is applicable to healthcare settings also where the systems have excess capacity to accommodate random variations. The need for application of queuing theory in healthcare settings is very important because these organizations are dealing with the well-being and human life is concerned. The patient satisfaction, time they spent in the queue while waiting for their turn to meet doctor as well as time they spent with the doctor, is very important for the proper working of any hospital as well as for the image of the hospital before the public. In this paper, Istudied about the patient satisfaction at Combined Hospital, Srinagar GarhwalUttarakhand.The paper explained the patients' demographic characteristics, nature of their illness, time they spent before reaching the hospital, on the queue to see the doctor and with the doctor. The patients' views about the queuing and patient behavior on the queue were also measured. The suggestions from patients on how the time they spend on the queue can be shortened were also taken.
\end{abstract}

Keywords: Queuing Theory, Healthcare system, patient behavior, arrival pattern and service pattern.

\section{Introduction}

Health is one of the major concern in today's stressful life and waiting in a queue in health care center is the biggest problem faced by the patients. In government hospitals, this problem is more catastrophic because of the low treatment cost as compared to the private clinics, people prefer government hospitals rather than private clinics. Long waiting times always causes patient dissatisfaction and also affect patient compliance with treatment regimens and clinical outcomes. Patient satisfaction is one of the major determinant of hospital functioning and also helps in improving the quality of the health services. It will also act as feedback for the health providers to improve the quality of the care they are providing to their patients. Looking from the point of view of management as well as economicbenefits improved quality of care and patient satisfaction will attract new patients to the government hospitals which will help government economically and will create happy and healthy people and so a healthier world.

Healthcare System in India and around the world has witnessed a phenomenal growth during last three decades. The basic reason behind raising this industry is the increasing rate of population and their demand for the healthcare service. So, health care systems have been challenged in recent years to deliver services to all the patient and high quality services with limited resources without delay. This issue for healthcare industry is a bottleneck issue because delay in service may result in death of a patient and congestion results into mismanagement of resource distribution and allocation to patient or staff members of the hospital as well. Health care resources are becoming increasingly limited and expensive, thereby placing greater emphasis on the efficient utilization of the resources and the corresponding level of service provided to patients. [1]

\section{Queuening Theory}

Queueing theory is the mathematical study of waiting lines and is concerned with the statistical description of the behavior of queues with findings. It is the branch of Operation Research as it is related to the customer satisfaction and the functionality of the service providers. The fundamental goal of Queueing Theory is to derive an analytical or mathematical model of customer needing service and use that model to predict queue lengths and waiting times. A queue or waiting line is formed when units (customersor clients)requiring service arrive at a service counter. [2]

A K Erlang first gave the concept of Queueing theory in 1913 when he created the models to describe telephone exchange. With the help of Queueing model we can find out the mean waiting time in the queue, mean service time, utilization of service facilities, distribution of the number of customers in the queue, distribution of the customers in the system, etc.The basic process of a Queueing System comprises of: (i) The arrival pattern,(ii) The service pattern,(iii) Queue discipline (FIFO: First In First Out, LIFO: Last In First Out, SIRO: Selection In Random Order, PIR: Priority in selection) , and (iv) Service mechanism. 


\section{International Journal of Science and Research (IJSR) \\ ISSN (Online): 2319-7064 \\ Index Copernicus Value (2013): 6.14 | Impact Factor (2015): 6.391}

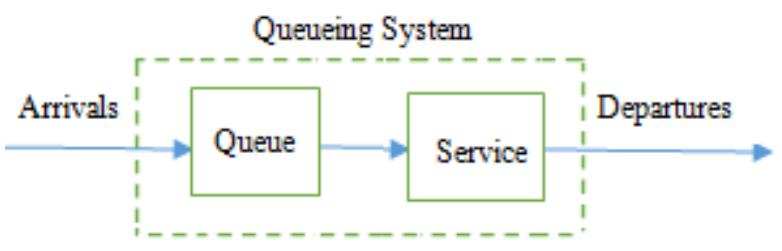

Parameters in Queueing Model

1. $\mathrm{n}=$ Number of customers(units) in the system.

2. $\mathrm{c}=$ number of parallel servers (OPD doctors in Combine Hospital Srinagar (G)).

3. $\lambda=$ (Arrival rate) It is the mean rate of arrivals per unit of time in the system.

4. $\mu=$ (Service Rate) It is the average number of customers served per unit of time.

5. $c \mu=$ Serving Rate when $\mathrm{c}>1$ in a system.

6. $\rho=$ utilization factor $(\lambda / \mathrm{c} \mu)$.

7. $\mathrm{P}_{\mathrm{o}}=$ Steady state Probability of all idle servers (doctors) in the system.

8. $\mathrm{P}_{\mathrm{n}}=$ Steady state Probability of exactly $\mathrm{n}$ patients in the system.

9. $\mathrm{L}_{\mathrm{q}}=$ Average number of patients in the queue.

10. $\mathrm{L}_{\mathrm{s}}=$ Expected number of patients in the system.

11. $\mathrm{W}_{\mathrm{q}}=$ Average waiting time a patients spends waiting in line excluding the service time.

$12 . \mathrm{W}_{\mathrm{s}}=$ The expected time a customer spends in the system.

\section{Materials and Methods}

Applicability of queuing theory is a relatively new concept in the Indian hospital industry with special reference to hospitals in Uttarakhand. So main purpose of this research study is to examine the applicability of waiting line or queuing theory is to analyze the congestion of patients in Combine hospital, Srinagar Garhwal. The data was collected on Monday to Saturday for a week. The mean arrival rates and the mean service rates were calculated from the data collected and the result was used to measure the performance of the entire system. Although the hospital opens by 9:00 am everyday but the working starts from 9:30 am.Atotalof 923 patients arrived for service during this one week of observation.

\section{Results}

\section{Demographics}

There were 384 (41.6\%) males and 539 (58.4\%) females, aged 1- 70 years. Two hundred thirty five $(25.46 \%)$ of the patients were students, 193(20.91\%) housewives, 200(21.67\%) civil servants, $76 \quad(8.23 \%)$ retired, 128(13.87\%) businessmen and 91(9.86\%) others.

Eighty nine (9.64\%) were illiterate, 109 (11.81\%) have primary education, 205(22.21\%) with secondary education and $402(43.55 \%)$ and $118(12.78 \%)$ are graduate and post graduate respectively.
Time spent on the queue [Table 1.]

\begin{tabular}{|c|c|c|}
\hline Time spent on the queue & Number & Percentage \\
\hline$<30 \mathrm{~min}$ & 324 & 35.1 \\
\hline $30-60 \mathrm{~min}$ & 443 & 48 \\
\hline $1-2 \mathrm{hrs}$ & 108 & 11.7 \\
\hline $2-3 \mathrm{hrs}$ & 31 & 3.36 \\
\hline $3-4 \mathrm{hrs}$ & 12 & 1.3 \\
\hline$>4 \mathrm{hrs}$ & 5 & 0.54 \\
\hline Total & 923 & 100 \\
\hline
\end{tabular}

Three hundred twenty four (35.1\%) patients spent less than 30 minutes on the queue before seeing the doctor, $443(48 \%)$ 30 - 60 min,108 (11.7\%) 1-2 hrs,31 (3.36\%) 2-3 hrs,12 (1.3\%) 3-4 hrs and only 5 (0.54\%)above 4 hrs.

\section{Patients' views on time spent on the queue before seeing} the doctor [Table 2.]

\begin{tabular}{|c|c|c|}
\hline Patient views & Number & Percentage \\
\hline Time is long & 438 & 47.45 \\
\hline Time is short & 133 & 14.41 \\
\hline Ok with time spent & 267 & 28.93 \\
\hline Can't say & 85 & 9.21 \\
\hline Total & 923 & 100 \\
\hline
\end{tabular}

Four hundred thirty eight (47.45\%) patients think that time they spent in the queue is very long and so it is annoying, while 267 (28.93\%) are satisfied with the time they spent on the queue before seeing the doctor, and 85(9.21) were undecided.

Patients' behavior in the queue [Table 3.]

\begin{tabular}{|c|c|c|}
\hline Patients' Behavior & Number & Percentage \\
\hline Wait for the turn & 672 & 72.81 \\
\hline Jump queue & 106 & 11.48 \\
\hline Join and then leave the queue & 63 & 6.83 \\
\hline Patients not seen in order & 39 & 4.23 \\
\hline Other lapses & 43 & 4.66 \\
\hline Total & 923 & 100 \\
\hline
\end{tabular}

It was observed that $672(72.81 \%)$ patients were patiently waiting for seeing doctor. The reason for this could be that being healthy is the need of every individual and for that they can even wait for their turn. But by applying the queueing model this waiting time can be reduced so that this time can be utilized in some productive work rather then wasting it in waiting in queue.106 (11.48\%) were seen jumping in the queue,43 (4.66\%) were combination of the above, and $63(6.83 \%)$ left the queue before their turn to be seen by the doctor.

Suggestions form patients on reducing the waiting time [Table 4.]

\begin{tabular}{|c|c|c|}
\hline Suggestions from patients & Number & Percentage \\
\hline Doctors should come on time & 76 & 8.23 \\
\hline More doctors required & 129 & 13.98 \\
\hline Satisfied with the service & 325 & 35.21 \\
\hline FCFS strictly applied & 254 & 27.52 \\
\hline other suggestions & 14 & 1.52 \\
\hline $\begin{array}{c}\text { waiting area should have proper sitting } \\
\text { arrangement }\end{array}$ & 125 & 13.54 \\
\hline Total & 923 & 100 \\
\hline
\end{tabular}

A lot of valuable suggestions from the patients were received which can surely be helpful in reducing the waiting 


\section{International Journal of Science and Research (IJSR) \\ ISSN (Online): 2319-7064 \\ Index Copernicus Value (2013): 6.14 | Impact Factor (2015): 6.391}

time. Three hundred twenty five (35.21\%) were satisfied with the service they received, 76 (8.23\%) suggested that doctors should come on time, a very high percentage 254 (27.52\%) suggested that first come first serve scenario should be strictly followed, while 125 (13.54\%) suggested that a proper sitting arrangements should be done.

Figures displaying arrival and service distribution of patient graphically

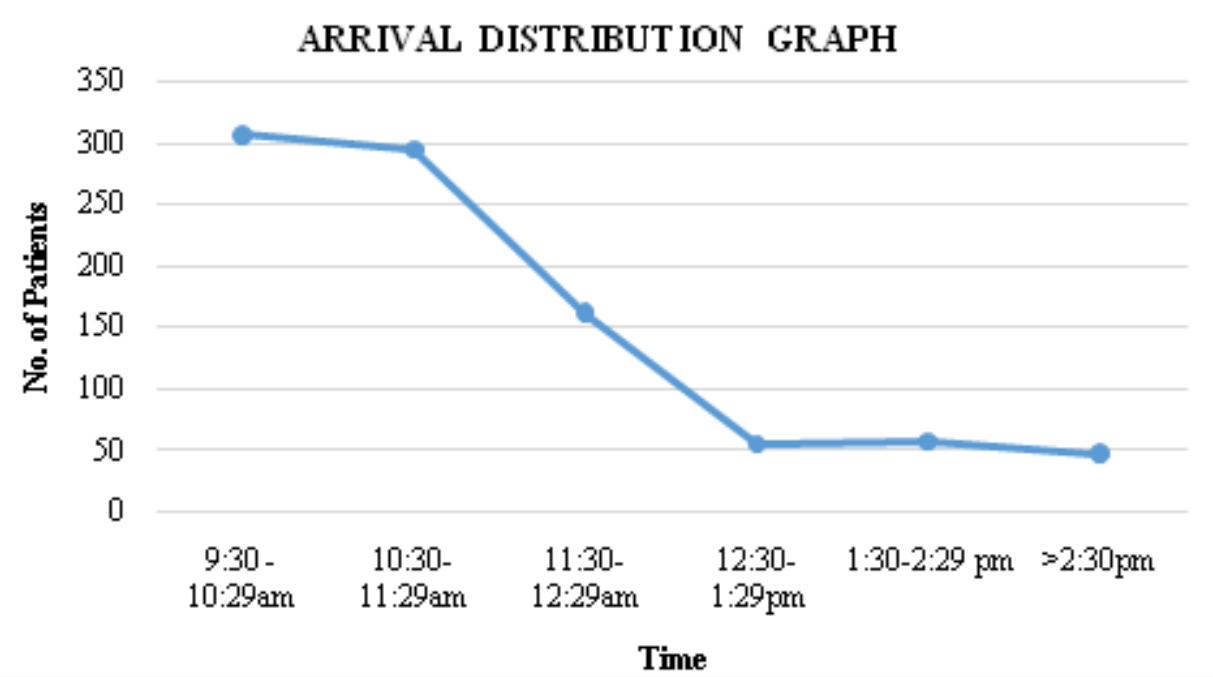

Figure 1: This figure is showing the hourly arrival distribution of patients during the study period

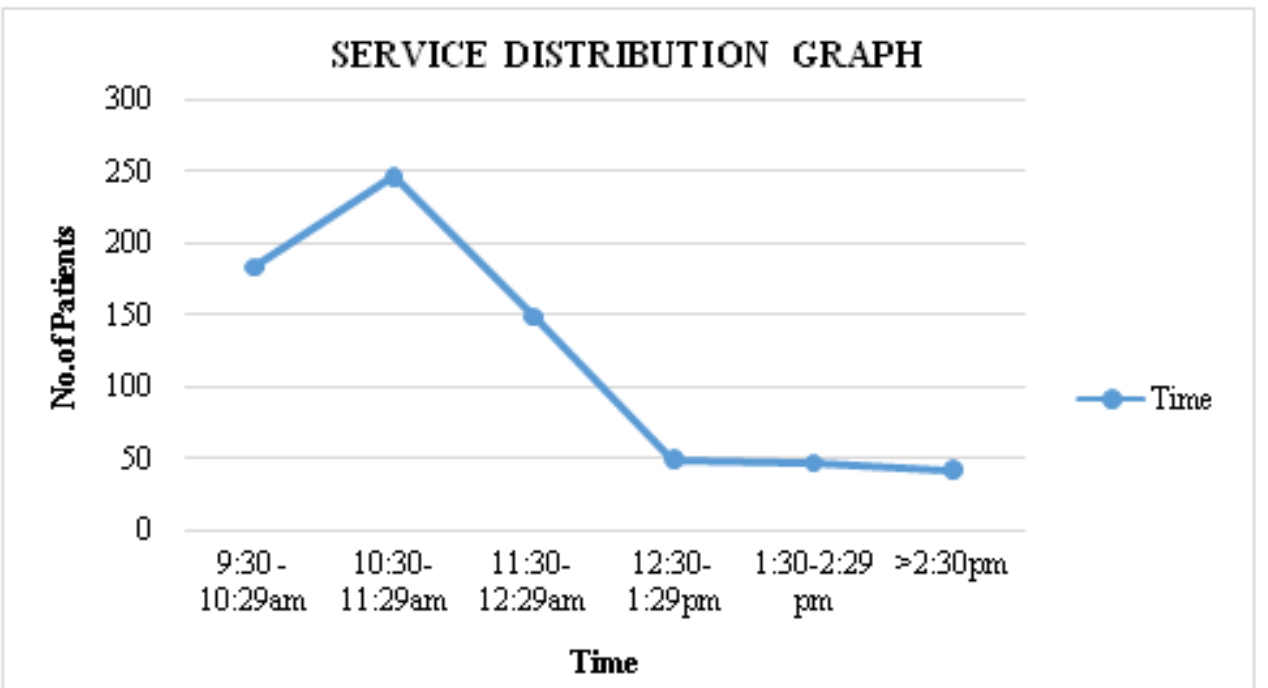

Figure 1: This figure is showing the hourly service distribution of patients during one week period

\section{Calculation of queuing parameters per day OPD [Table 5.]}

\begin{tabular}{|c|c|c|c|c|c|c|}
\hline \multirow{2}{*}{ Parameters } & \multicolumn{6}{|c|}{ Days } \\
\hline & Mon & Tue & Wed & Thu & Fri & Sat \\
\hline Patient Arrival Rate $(\lambda)$ per minute & 26.833 & 27.333 & 25.333 & 24.000 & 24.333 & 26.000 \\
\hline Service Rateper server $(\mu)$ per minute & 17.500 & 20.500 & 16.333 & 21.000 & 21.833 & 21.500 \\
\hline Utilization Factor (a) & 0.767 & 0.667 & 0.776 & 0.571 & 0.557 & 0.605 \\
\hline Traffic intensity $(\rho)$ & 1.533 & 1.333 & 1.551 & 1.143 & 1.115 & 1.209 \\
\hline Average number of patient in queue $\left(L_{q}\right)$ & 2.186 & 1.067 & 2.340 & 0.554 & 0.502 & 0.697 \\
\hline Average number of patient in system $\left(\mathrm{L}_{\mathrm{s}}\right)$ & 3.719 & 2.400 & 3.891 & 1.697 & 1.616 & 1.906 \\
\hline Average time patient spends in queue $\left(\mathrm{W}_{\mathrm{q}}\right)$ in min. & 4.888 & 2.341 & 5.543 & 1.385 & 1.238 & 1.608 \\
\hline Average time patient spends in system $\left(W_{s}\right)$ in min. & 8.317 & 5.268 & 9.216 & 4.242 & 3.986 & 4.399 \\
\hline The probability that all servers are idle $\left(P_{0}\right) \%$ & 13.208 & 20.000 & 12.644 & 27.273 & 28.431 & 24.638 \\
\hline The probability arriving customer waits $\left(\mathbf{P}_{w}\right) \%$ & 66.540 & 53.333 & 67.746 & 41.558 & 39.882 & 45.568 \\
\hline
\end{tabular}

This table displays'different queueing parameters showing that average time patient spends in the queue in minutes is between $1-6$ minutes. As the values of traffic intensity $\rho>1$ which means that there is very heavy congestion in the system. The maximum probability that all servers are idle is
20 on Tuesday. Detailed description is given under discussion. 


\section{International Journal of Science and Research (IJSR) \\ ISSN (Online): 2319-7064 \\ Index Copernicus Value (2013): 6.14 | Impact Factor (2015): 6.391}

\section{Discussion of Results}

We can saw that the probability for servers tobe busy was 1.533 and idle $13.21 \%$ of the time on Monday. The average number of patients waiting in aqueue was $\mathrm{Lq}=2.19$ patients and the average number of patients waiting in the system was Ls $=3.72$ per 2-server. The waiting time in a queue per server was $\mathrm{W}_{\mathrm{q}}=4.89 \mathrm{~min}$ and average time a patient spends in thesystem was $\mathrm{W}_{\mathrm{s}}=8.32 \mathrm{~min}$.

Comparing the mean arrival rates of patients per hour on the days that the study was undertaken, itwas observed that Tuesday had the highest mean arrival of 27.333 patients/hour and Thursday had the least arrivalrate of 24 patients/hour. Analysis of the system utilization factor of the servers shows that among all the six number of days, the servers were the busiest of allon Wednesday with a utilization factor of $77.6 \%$.

The mean arrival rate of patients everyday was greater than the mean service rate of patients on that same day, which means that the waitingline would be formed which would increase indefinitely; the service facility would always be busy. Thisaccounted for the greater values of utilization factors each day. Analysis of the entire system of the OPD shows that queue length increases when the system is very busy. Thatis, when the utilization factor of the system is very high, it tends to increase patients waiting time.

On the average the total number of minutes a patient spends in the queue before seeing a doctor are asfollows;4.888 minutes on Monday, 2.341 minutes on Tuesday, 5.543 minutes on Wednesday, 1.385 minutes onThursday,1.238 minutes on Friday and 1.608 minutes on Saturday. Again, the average number of minutes a patient spent in the entiresystemare as follows; 8.317 minutes on Monday, 5.268 on Tuesday, 9.216 minutes on Wednesday, 4.242 minutes on Thursday , 3.986 minutes on Friday and 4.399 minutes on Saturday.

In total, it was found out that patients had to wait for long in the queues of the OPD section of the hospital which is resulting to the higher congestion in the hospital. In future studies we intend to extend the research for developing the queueing model to reduce the congestion.

\section{References}

[1] Dr. KiranSoni, 2Prof. (Dr.) KaruneshSaxena “AN_EMPIRICAL_STUDY_ON_APPLICABILITY_OF_ WAITING_LINE_MODEL_IN_SELECTED_HOSPITAL S"_ijariie1213_volume_1_13_page_268_282.

[2] Sundarapandian, V. (2009). "7. Queuing Theory". Probability, Statistics and Queuin Theory, PHI Learning ISBN 8120338448.

[3] Sathy, Thomas L. (1961): Elements of queueing theory with applications, McGraw Hill New York Toronto London,.

[4] Lee, A.M. (1958): Applied queueing theory, Mac Millian and company londern.

[5] Davis M. M, Vollmann T. E (1990). A framework for Relating Waiting Time and Customer Satisfaction in a
Service Operation, Journal of Services Marketing, 4 (1) 61-69.

[6] Singh V (2007). Use of Queuing Models in Health Care, Department of Health Policy and Management, University of Arkanses for medical science.

[7] Fomundans and Hermann. A survey of Queuing theory applications in healthcare (12) 1 SR Technical Report 24. 2007

[8] Nosek RA, Jr, Wilson JP. Queuing theory and customer satisfaction, a review of terminology, trends, and applications to pharmacy practice. Hosp Pharm. 2001;36:275.

[9] Taylor S, Kuljis J. Simulation in health care management: modelling an outpatient clinic. OR Insight.1998;11(3):7-11.

[10]Eldabi T, Irani Z, Paul RJ. A proposed approach for modelling health-care systems for understanding. J Manage Med. 2002;16(2/3):170-87. [PubMed] 